\title{
Electromagnetic radiation of low intensity as a factor of change of phenolic compounds content
}

\author{
Svetlana Shysh $^{*}$, , Zhanna Mazets ${ }^{2}$, Hanna Shutava $\left(\right.$ id ${ }^{1}$, Olga Sysha², Yulia Gorgun² \\ ${ }^{1}$ Central Botanical Garden, NAS of Belarus \\ ${ }^{2}$ Belarusian State Pedagogical University named M. Tank
}

\begin{abstract}
The influence of low-intensity electromagnetic radiation (EMR) on the content of phenolic compounds (PC) in plants on different stages of ontogeny is discussed. A medicinal plant (Calendula officinalis L.) and agricultural crop Fagopyrum sagittatum G., diploid varieties and tetraploid varieties were chosen as objects of study. Microwave EMR in two frequency bands, $53.57-78.33 \mathrm{GHz}$ (wide range mode) and 64.00-66.00 GHz (narrow range mode), has been selected to learn the physical effects on seeds, with a treatment exposure time of 20,12 , or $8 \mathrm{~min}$. The experiments were conducted under laboratory and field conditions. Treated and control seeds were germinated by $100 \mathrm{pcs}$ in a growth chamber on moistened filter paper at $22-24^{\circ} \mathrm{C}$ in the dark and placed on the daylight from the third day. The level of PC in the seedlings was measured with the Folin-Ciocalteu reagent. It was found that in the EMR pretreated C. officinalis seedlings the level of PC is maximal on 14th day of germination. The wide mode treatment for 12 min results in a two-fold increase in the level of PC in juvenile shoots with respect to control. Different constitutional levels of phenolic compounds in the leaves of diploid and tetraploid varieties of $\mathrm{F}$. sagittatum in the most critical phases of ontogeny were found. It is recommended to use EMR with a $12 \mathrm{~min}$ exposure time for C. officinalis. The narrow frequency mode with an exposure time of $20 \mathrm{~min}$ is preferable to use for most varieties of F. sagittatum.
\end{abstract}

\section{ARTICLE HISTORY}

Received: 28 March 2018

Revised: 29 June 2018

Accepted: 06 September 2018

\section{KEYWORDS}

Electromagnetic radiation of microwave range,

Calendula officinalis $L$.

Fagopyrum sagittatum $G$., Phenolic compounds.

\section{INTRODUCTION}

As a protection against various stressors plants use protective mechanisms associated with the synthesis and accumulation of specific metabolites, called secondary. Phenolic compounds (PC) are of great importance for the performance of this function. The properties of PC in the plant organism are numerous and varied. They are characterized by high physiological activity and antioxidant properties. Their content in the plant is determined by the type of plant, as well as by the conditions of growth, and, therefore, these substances are markers of stress conditions in plants [1,2]. The influence of lowintensity electromagnetic radiation (EMR) on plants is studied by researchers from different countries for 50 years [3-12]. However, the mechanism of its action is not yet fully understood, but it has already

CONTACT: Svetlana Shysh $₫$ svetlana.shysh@gmail.com 国 The Central Botanical Garden, National Academy of Sciences of Belarus, Surganova St, 2B, 220072, Minsk, Belarus

Phone: +375(33)6384808 FAX: +375(17)2841484 
been established that the activation of the antioxidant system of plants, including low- and highmolecular components, occurs during the treatment of EMR. Therefore, the study of the state of this system, and in particular low-molecular antioxidants, is important for understanding the mechanism of interactions of EMR with plants.

It is important for Belarus to look for optimal conditions and methods for cultivating these crops. There is a problem when growing marigold to obtain high-quality pharmaceutical raw materials, environmentally pure and containing a sufficient number of biologically active substances, as well as increasing crop yields. When buckwheat is grown in the conditions of Belarus, the issue of yield comes first. As it is known from literature, the level of phenolic compounds in a plant affects on the resistance to environmental factors and crop yields [13]. It is necessary to use stimulating factors to increase the agro technical characteristics of plants. For that purpose we choose the electromagnetic treatment of the millimeter range of low-intensity which has proved itself well on a number of vegetable crops both in Belarus and abroad.

\section{METHOD}

A medicinal plant Calendula officinalis L. ('Machroviy 2000', Belarus) and agricultural crop Fagopyrum sagittatum G. diploid varieties ('Kypava' and 'Phenix') and tetraploid varieties ('Alexandrina', 'Anastasia', 'Martha', Belarus) were chosen as objects for the study.

Microwave electromagnetic radiation in two frequency bands has been selected to study the physical effects on seeds: Mode 1 (processing frequency 53.57-78.33 GHz - wide range) with 20 minutes of treatment exposure (R1), 12 minutes (R1.1), 8 minutes (R1.2) and mode 2 (64.00-66.00 GHz processing frequency - narrow range), with the same 20 minutes of treatment exposures (R2), 12 minutes (R2.1), 8 minute (R2.2). Seed treatment was carried out at the Institute for Nuclear problems of BSU in a laboratory microwave installation for seed treatment of various agricultural crops in a wide frequency range (37 to $120 \mathrm{GHz}$ ) with infinitely adjustable power from 1 to $10 \mathrm{~mW}$ [14].

The experiment was conducted in the laboratory and field conditions. In the laboratory treated and control seeds were germinated by 100 pcs in a growth chamber on moistened filter paper at a temperature $22^{\circ} \mathrm{C}$ in the dark for 3 days. Next the germinating seeds were transferred to a room with natural light $\left(24^{\circ} \mathrm{C}, 12\right.$-hour photoperiod). The length and mass of the roots and seedlings have been evaluated. Preparation of extracts of all samples under study has been carried out according to the State Pharmacopoeia of the Republic of Belarus [15]. The level of PC was measured with Folin-Ciocalteu reagent at a wavelength of $730 \mathrm{~nm} \mathrm{[16]} \mathrm{on}$ spectrophotometer Agilent 8453. Calculation of the PC level has been carried out on a calibration curve, gallic acid was used as a standard. The range of concentrations of gallic acid was $0.10-1.0 \mathrm{~g} / \mathrm{l}$. The content of PC samples was expressed as equivalent to gallic acid in $\mathrm{g} / 100$ $\mathrm{g}$ of dry weight (DW). The experiments were performed in 3 -fold biological and analytical replicates. Untreated seeds served as control. The results were processed using the statistical package M. Excel and Stadia 8.0. The figure and tables show the mean values of the definitions and their standard deviations.

\section{RESULTS AND DISCUSSION}

It is well known that the biosynthesis of PC in different phases of plant growth and development has an oscillatory nature. Plants can either grow PC synthesis or decrease their contents in the extreme conditions. So a decrease in temperature leads to an increase in the content of PC according to the literature [17]. Insufficient sunny days, violation of mineral nutrition and water regime also affect on the qualitative and quantitative composition of the PC [13, 18-19].

However, it is known that the correct selection of modes of EMR treatment contributes to an increase in the content of PC, especially under the laboratory conditions [20-21], but in 
the field experiment the result is significantly offset by abiotic factors [22]. Accumulation of PC in raw materials may to increase, that we previously established on the plants of marigold in 2014-2015 [19], and to be at the control level 2016-2017 year (Table 1, on 60 ${ }^{\text {th }}$ day in the flowering phase).

Table 1. The content of PC in C. officinalis seedlings (on 7th day and on 14th day - laboratory conditions) and inflorescence (on 60th day - field experiment), g/100 g DW

\begin{tabular}{cccccccc}
\hline Variant & Control & $\mathrm{R} 1$ & $\mathrm{R} 1.1$ & $\mathrm{R} 1.2$ & $\mathrm{R} 2$ & $\mathrm{R} 2.1$ & $\mathrm{R} 2.2$ \\
\hline On $7^{\text {th }}$ day & $2.6 \pm 0.2$ & $3.3 \pm 0.04$ & $5.0 \pm 0.6$ & $2.7 \pm 0.1$ & $2.3 \pm 0.2$ & $1.7 \pm 0.3$ & $3.6 \pm 0.1$ \\
\hline On $14^{\text {th }}$ day & $2.6 \pm 0.1$ & $2.96 \pm 0.4$ & $3.5 \pm 0.4$ & $5.0 \pm 0.5$ & $4.1 \pm 0.8$ & $3.0 \pm 0.6$ & $6.2 \pm 0.1$ \\
\hline On $60^{\text {th }}$ day & $2.5 \pm 0.1$ & $2.4 \pm 0.1$ & $2.7 \pm 0.1$ & $2.4 \pm 0.1$ & $2.5 \pm 0.04$ & $2.3 \pm 0.4$ & $2.5 \pm 0.2$ \\
\hline
\end{tabular}

It was established that the influence of EMR on the PC accumulation in juvenile marigold seedlings under controlled conditions has a pronounced dependence from the exposure of EMR (Tabl. 1). An increase in the concentration of phenolic compounds in these seedlings after EMR treatment has been noted. Exposure during $8 \mathrm{~min}$ led to a maximum increase in the PC level. In $7^{\text {th }}$-day seedlings, the level of phenolic compounds was above the control value in R1 and R1.1 on 27 and $92 \%$, respectively, and lower in R2 and R2.1 on 12 and 33\% relative to control. An increase in the amount of PC after EMR treatment in $14^{\text {th }}$ day plants of calendula was noted. The level of PC increases from 14 to $140 \%$ with respect to control, as much as it was in R1.2 and R2.2 to the $14^{\text {th }}$ day. Shifts in the PC level under the influence of EMR were observed mainly in juvenile marigold plants, but they were practically absent at the time of flowering (Table 1).

It was noted that there is no direct relationship between the PC level and growth processes in the experiment with juvenile marigold sprouts (Table 1, Figure 1). The level of PC in control and $R 1.2$ coincide on the $7^{\text {th }}$ day, but the growth processes of the experimental seedlings prevail over the control values. It was established that R1.2 has the highest morphometric parameters, R2.1 has the lowest PC level on 33\% below the control values, but the growth rate was higher than the control values and the predominance of root growth has been observed. The predominance of growth and extension processes has been noted for the regimes of the first group because the parameters of root and sprout length have the maximum values. Activation of growth processes and an increase in the level of PC took place in the $14^{\text {th }}$ day sprouts. Dependence of the growth rate and amount content of PC from the time of exposure has been noted for the regimes of the first group, maximum effect during treatment has been established through the 8 minutes (R1.2). It was noted for the second group of regimes (64-66 GHz) that stimulation of growth has been accompanied by an increase in the number of PC when EMR was processed for 12 minutes (R2.1). 


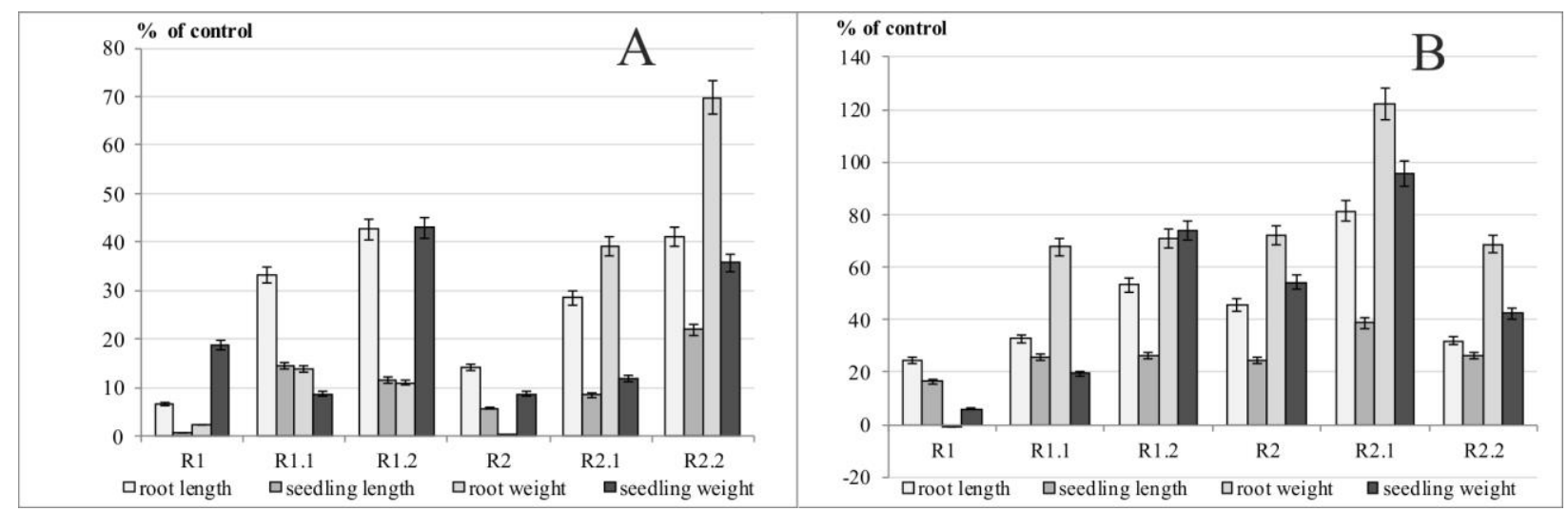

Figure 1. Effect of EMR on morphometric parameters of juvenile marigold plants: $\mathrm{A}-$ on the $7^{\text {th }}$ day; $\mathrm{B}-$ on the $14^{\text {th }}$ day

Thus, it was found that an increase in content of PC has been occurred to the $14^{\text {th }}$ day as a result of the influence of EMR. The dependence between the quantitative content of PC and exposure was established. Treatment by R1.2 led to an increase in 2 times in the level of PC in juvenile shoots with respect to control.

Different constitutional level of the PC in the leaves of diploid and tetraploid varieties of Fagopyrym sagittatum $\mathrm{G}$. in the most critical phases of ontogenesis of plant development such as the initial stages ( $7^{\text {th }}$ day) and the period of plants mass flowering ( $69^{\text {th }}$ day) has been established during the research (Table 2).

Table 2. Influence of low-intensity electromagnetic radiation on accumulation of PC in leaves of diand tetraploid varieties of Fagopyrym sagittatum, g/100 g DW

\begin{tabular}{lcccccc}
\hline \multirow{1}{*}{ Variant } & \multicolumn{3}{c}{ On $7^{\text {th }}$ day } & \multicolumn{3}{c}{ On 69 ${ }^{\text {th }}$ day (mass flowering) } \\
\cline { 2 - 7 } & Control & R2 & R2.1 & Control & R2 & R2.1 \\
\hline 'Alexandrina' & $7.4 \pm 0.4$ & $5.1 \pm 0.3$ & $2.9 \pm 0.2$ & $12.2 \pm 0.7$ & $12 \pm 0.5$ & $11.3 \pm 0.6$ \\
\hline 'Anastasia' & $6.6 \pm 0.4$ & $7.8 \pm 0.4$ & $9.3 \pm 0.5$ & $11.4 \pm 0.6$ & $10.8 \pm 0.5$ & $12.7 \pm 0.6$ \\
\hline 'Martha' & $5.9 \pm 0.03$ & $8.6 \pm 0.4$ & $7.8 \pm 0.4$ & $11 \pm 0.6$ & $11.2 \pm 0.1$ & $11.2 \pm 0.5$ \\
\hline 'Kupava' & $2.8 \pm 0.2$ & $0.5 \pm 0.1$ & $1.5 \pm 0.1$ & $11 \pm 0.5$ & $10.5 \pm 0.5$ & $10.2 \pm 0.5$ \\
\hline 'Phenix' & $2.2 \pm 0.1$ & $2.7 \pm 0.1$ & $1.6 \pm 0.1$ & $8.9 \pm 0.4$ & $11.3 \pm 0.6$ & $1.6 \pm 0.1$ \\
\hline
\end{tabular}

It was noted that in all studied periods among the tetraploid varieties Fagopyrym sagittatum the control of 'Martha' has the minimum content of these metabolites and 'Alexandrina' has the maximum one.

It was revealed that under the influence of the EMR regimes the content of PC decreased with respect to the control with a reduction in the exposure time from 20 (R2) to 12 minutes (R2.1) on $30.7 \%$ and $60.7 \%$ respectively in 'Alexandrina'. 'Martha' reacted differently to EMR regimes. The level of phenolic compounds was increased on $46.3 \%$ under the influence of R2 and on $31.8 \%$ under R2.1 on the initial stages, and there was practically no difference between control and experience on the $69^{\text {th }}$ day. A different trend was noted in 'Anastasia' so R2.1 significantly (on 41\%) increased the level of PC at the initial stages and the stimulatory effect decreased to $11.1 \%$ to $69^{\text {th }}$ day. It was noted that the reaction of 'Anastasia' to R2 depended on the ontogenesis stage. There was an increase in the content of these metabolites on $18.2 \%$ on the $7^{\text {th }}$ day and decrease on $5.3 \%$ was revealed to the period of mass flowering.

A specific reaction of diploid varieties of Fagopyrym sagittatum on the EMR regimes on the accumulation of phenolic substances in shoots and leaves has been noted. It was established 
that R2.1 reduced the level of these compounds in both diploid varieties at the initial stages of vegetation on $44.4 \%$ ('Kupava') and $27 \%$ ('Phenix'). It was noted that content of PC to $69^{\text {th }}$ day in 'Kupava' lowered to $6.84 \%$, but in 'Phenix' it increased on $82 \%$ relative to control on this date. It was noted that R2 sharply inhibited the accumulation of these metabolites on $83 \%$ in 'Kupava' at the initial stages of ontogeny and at the period of mass flowering the differences were smoothed out. The level of phenolic compounds under the influence of R2 in 'Phenix' increased on $23.4 \%$ and $27 \%$ on the $7^{\text {th }}$ and $69^{\text {th }}$ days of ontogenesis respectively.

Table 3. Effect of EMR regimes on the height of buckwheat plants of three tetraploid varieties on the $7^{\text {th }}$ and $69^{\text {th }}$ day of development

\begin{tabular}{|c|c|c|}
\hline \multirow[t]{2}{*}{ Variant } & \multicolumn{2}{|c|}{ Length, $\mathrm{cm}$} \\
\hline & on $7^{\text {th }}$ day & on $69^{\text {th }}$ day \\
\hline \multicolumn{3}{|c|}{ 'Alexandrina' } \\
\hline Control & $9.2 \pm 0.4$ & $85.6 \pm 4.3$ \\
\hline $\mathrm{R} 2$ & $9.4 \pm 0.3$ & $82.5 \pm 4.1$ \\
\hline $\mathrm{R} 2.1$ & $9.5 \pm 0.2$ & $81.2 \pm 4.1$ \\
\hline \multicolumn{3}{|c|}{ 'Anastasia' } \\
\hline Control & $6.5 \pm 0.2$ & $89.4 \pm 4.5$ \\
\hline R2 & $6.7 \pm 0.2$ & $81.9 \pm 4.1$ \\
\hline R2.1 & $5.5 \pm 0.2$ & $86.3 \pm 4.3$ \\
\hline \multicolumn{3}{|c|}{ 'Martha' } \\
\hline Control & $6.2 \pm 0.3$ & $87.1 \pm 4.4$ \\
\hline R2 & $5.7 \pm 0.3$ & $83.0 \pm 4.2$ \\
\hline R2.1 & $5.7 \pm 0.3$ & $81.6 \pm 4.1$ \\
\hline
\end{tabular}

Almost everywhere there is no information about the influence character of PC on the nature of plant growth processes. Therefore, we attempted to assess the effect of EMR regimes on the height of plants on the $7^{\text {th }}$ and $69^{\text {th }}$ day of ontogeny and compare it with the level of PC (Table 2 and 3). It was noted that a significant decrease in PC under the influence of the EMR regimens with respect to control of 'Alexandrina' practically didn't affect on the growth of seedlings at the initial stages of ontogenesis. It was revealed that in the period of mass flowering of plants a slight decrease in the level of these metabolites a little bit inhibited the growth of plants of this variety and especially in the case of R2.1 (It reduced on 5.2\% compared to the control (Table 3)). A significant increase of PC (41\%) under the influence of R2.1 was accompanied by a decrease in the intensity of the growth processes on the early stages on $15.4 \%$ in 'Anastasia'. The level of these compounds increased on $11.1 \%$ to the period of mass flowering, but the height of the experimental plants slightly differed from control one of 'Anastasia'. It was revealed that in 'Anastasia' R2 had practically no effect on the length of shoots to the $7^{\text {th }}$ day, whereas it inhibited the growth processes on $8 \%$ relative to control to the $69^{\text {th }}$ day. It was found that a significant increase in the level of PC in the initial stages of ontogeny inhibited the growth processes during this period on $7.9 \%$ (R2) and $15.4 \%$ (R2.1), and to the period of mass flowering the magnitude of this effect decreases to 4,7\% (R2) and $6.3 \%$ (R2.1) in plants of 'Martha'.

Thus, the shifts in the level of the phenolic compounds relative to the control were gradually reflected on the character of the growth processes, and the magnitude and direction of the deviations from the control values depended on the individual characteristics and the physiological state of the object under study. 


\section{CONCLUSION}

Shifts in the accumulation of compounds of phenolic nature are one of the sides of the interaction mechanism of millimeter-wave electromagnetic radiation with plant objects. The consequences of seeds processing by EMR were observed for juvenile plants up to 14 days and by the time of flowering the after-effect was practically removed and had no significant effect on the accumulation of the phenolic compounds in all investigated objects. Variety-specific shifts were detected under the influence of EMR regimes in the accumulation of the phenolic substances in sprouts and leaves of di- and tetraploid varieties of buckwheat, which had an impact on the nature of the growth processes.

Change in the level of compounds of phenolic nature confirms the opinion that the EMR of the microwave range in the studied regimes is a small stress factor, and the responses that develop in the treated plants can be considered as phases of phytostress.

It was found that the maximum deviations in PC level are noted at the initial stages of ontogeny. The magnitude of the deviation is species- and variety specific. The amplitude of the differences between the control and experimental variants is reduced near the flowering period. Established changes in the content of PC under the influence of EMR allow to select the exposure time for the regulation of growth processes of cereals and medicinal crops for the purpose of using them for the industrial cultivation of these plants. Species - and varietyspecific changes in the content of secondary metabolites under the influence of EMR allow to choose the exposure time for the regulation of the growth processes of cereals and medicinal crops for the purpose of using them in the industrial cultivation of these plants. It is recommended to use EMR in the exposure of 12 minutes (R1.1 or R2.1) for Calendula officinalis. It is better to use mode 2 with a time of exposure of 20 minutes for most varieties of Fagopyrym sagittatum and for 'Anastasia' - R2.1 for 12 minutes duration of EMR.

\section{Acknowledgements}

The authors are grateful to Dr. Valentina N. Rodionova, Institute for Nuclear Problems of the Belarusian State University, for seed treatment.

\section{ORCID}

Hanna Shutava (iD) https://orcid.org/0000-0001-5312-0880

\section{REFERENCES}

[1]. Zaprometov, M.N. (1993). Physiology and biochemistry of flavonoids. J. Physiology of plants, 40(6), 921-931. (in Russian)

[2]. Gorgun, Y., Mazets, Z., Shysh, S., Elovskaya, N. (2017). Influence of low-intensity electromagnetic radiation on the dynamics of accumulation of phenolic compounds in buckwheat plants tetraploid. "Modern Problems of Natural Science in Science and the Educational Process» Materials of the Republican Scientific and Practical Conference. Minsk (in Russian).

[3]. Jambazishvili, S.N. (1974). Presowing treatment of seeds of sugar beet by various electrophysical methods and their influence on productivity and quality of root crops: the dissertation author's abstract the candidate of agricultural sciences: 06.01.09, Tbilisi (in Russian)

[4]. Novikova, G.V. (1980). Substantiation and research of technological process of influence of EMF microwave on seeds of vegetable cultures: the dissertation of the candidate tehn. sciences: 05.20.01., Chelyabinsk (in Russian)

[5]. Tambiev, A.H., Gusev, M.V., Kirikova, N.N., Beckiy, O.V., Gulaev, U.V. (1986). Stimulation of growth of cyanobacteria by millimeter electromagnetic radiation of low 
intensiveness. Trade Exibition Microbe-86. XIX Intern. Congr. Microbiol., September 713:Abstr. - Manchester, England, 1986. P. 380.

[6]. Deviatkov, N.D., Golant, M.B., Beckiy, O.V. (1991). Millimeter waves and their role in life processes, Moscow (in Russian)

[7]. Karpovich, V.A., Ermolovich, A.A., Mikhalenko, E.G., Barashkova, G.P., Novikov, O.T. (2004). New stimulating and disinfecting microwave technology for presowing processing of vegetable seeds. Agropanorama. 4, 17. (in Russian)

[8]. Klunduk, G.A. (2004). Substantiation of electrotechnological regimes of microwave treatment of flax seeds: the dissertation of the candidate tehn. sciences: 05.20.02. Krasnoyarsk, 156. (in Russian)

[9]. Tambiev, A.H., Kirikova, N.N., Beckiy, O.V., Gulaev, U.V. (2003). Millimeter waves and photosynthesizing organisms. J. Radio engineering, 175. (in Russian)

[10]. Tambiev, A.H. (2009). Regularities manifested by the action of low-intensity waves on photosynthetic organisms. J. Millimeter waves in biology and medicine, 56(4), 56-68. (in Russian)

[11]. Chilochi, A.A., Tyurina, Zh. P., Klapko, S.F., Stratan, M.V., Lablyuk, S.V., Dvornina, E.G., Kondruk, V.F. (2011). Effect of millimeter-range electromagnetic radiation on the biosynthesis of extracellular hydrolytic enzymes in Aspergillus and Penicillium micromycetes J. Surface Engineering and App. Electrochem, 47(6), 558-564.

[12]. Debouzya, J.-C., Crouziera, D., Dabouisa, V., Malabiaub, R., Bacheleta, C., Perrina, A. (2007) Effets biologiques des rayonnements millimétriques (94 GHz). Quelles conséquences à long terme? Biologic effects of millimeteric waves $(94 \mathrm{GHz})$. Are there long term consequences? J. Pathologie biologie, 55(5), 246-255.

[13]. Volynets, A.P. (2013). Phenolic compounds in the life of plants. Minsk (in Russian)

[14]. Karpovich, B.A., Rodionova, V.N. (2003). The method of presowing treatment of seeds of vegetable or grain crops. Patent of Belarus, №5580. (in Russian)

[15]. State Pharmacopoeia of the Republic of Belarus (2008) V.2, p.381. (in Russian)

[16]. Wang, M., Simon, J., Aviles, I., He, K., Zheng, Q., Tadmor, Y. (2003). Analysis of antioxidative phenolic compounds in artichoke (Cynara scolymus L.) J. of agricultural and food chemistry, 51(3), 601-608.

[17]. Fuksman, I.L. (1999) Influence of natural and anthropogenic factors on the metabolism of substances of secondary origin in woody plants: the dissertation author's abstract of the doctor of biol. sciences: 03.00.16, St. Petersburg. (in Russian)

[18]. Zaprometov, M.N. (1974) Basics of biochemistry of phenolic compounds. Moscow. (in Russian)

[19]. Lomboeva, S.S., Tankhaeva, L.M., Olennikov, D.N. (2008) Dynamics of accumulation of flavonoids in the aerial part of the ortilia with a one-sided (Orthilia secunda (L.) House) J. Chemistry of plant raw material, 3, 86-88. (in Russian)

[20]. Kopach, O.V., Pushkina, N.V., Kuzovkova, A.A., Karpovich, V.A. (2015). Exposure of ultra high frequency low power electromagnetic field on the biologically active substances biosynthesis in Silybum marianum L. cell cultures. J. Proceedings of the National Academy of Sciences of Belarus, Biological Series, 2, 5-8. (in Russian)

[21]. Kovzunova, O.V., Pushkina, N.V., Azizbekian, S.G. (2017) In vitro culture Silybum marianum (L.) as a potential source of target BAS. J. Problems of biological, medical and pharmaceutical chemistry, 20(7), 3-6. (in Russian)

[22]. Shysh, S., Mazets, Z., Shutava, H. (2017). Efficiency of water and water-alcohol extraction of Calendula officinalis raw by using various kinds of presowing processing. J. Problems of biological, medical and pharmaceutical chemistry, 6, 35- 40. (in Russian) 